\title{
Evaluation of Stripping Problem in Terms of Additive Types and Ratios in Asphalt Pavements
}

\author{
Celaleddin Ensar ŞENGÜL ${ }^{1}$ \\ Atakan AKSOY ${ }^{2}$ \\ Erol İSKENDER ${ }^{3}$
}

\begin{abstract}
Stripping in asphalt mixtures is the one of foremost distress mechanisms. To prevent stripping, fatty acids (AS) and hydrated lime (HL) additives are often used as anti-stripping additives. The determination of the correct usage ratios of these additives and the storage stability of bitumen constitutes important research topics for anti-stripping additive applications. Three surfactants and hydrated lime were used in three ratios to evaluate the effect of additive ratio and type. Indirect tensile strength (ITS) values obtained from samples with one and three cycle modified Lottman conditioning and indirect tensile strength ratios (ITSRs) were interpreted in the context of water damage. The load-carrying capacity of the conditioned mixtures increased significantly. Even if the degree of damage was considerably increased at the end of three cycles, the integrity of the mixtures was maintained. Both AS and HL significantly increased water damage resistance. Modified Lottman conditioning has an observable level of damage. Additives remained functional and maintain their mechanisms of benefit, especially in the event of a high degree of damage.
\end{abstract}

Keywords: Asphalt pavement, stripping, modified Lottman test, amine surfactants, hydrated lime.

\section{INTRODUCTION}

The problem of water damage (stripping) in asphalt pavements is one of the most complex pavement problems. Various additives are used to prevent or minimize stripping and a high degree of emphasis is placed on the design phase. Although the subject is evaluated with qualitative and quantitative test methods, there is no internationally accepted method in terms

\section{Note:}

- This paper was received on September 29, 2020 and accepted for publication by the Editorial Board on January 11, 2022.

- Discussions on this paper will be accepted by September 30, 2022.

- https://doi.org/10.18400/tekderg.798398

1 General Directorate of State Hydraulic Works, Fourteenth Regional Directorate, Istanbul, Turkey celensen@dsi.gov.tr - https://orcid.org/0000-0003-0998-028X

2 Karadeniz Technical University, Civil Engineering Department, Trabzon, Turkey aaksoy@ktu.edu.tr - https://orcid.org/0000-0001-5232-6465

3 Karadeniz Technical University, Civil Engineering Department, Trabzon, Turkey eiskender@ktu.edu.tr - https://orcid.org/0000-0001-7934-839X 
of evaluating the performance level of the methods used and the long-term performance issues.

Highway institutions expresses the need for a reliable and practical laboratory method that can simulate moisture damage in the field, even if continuous improvement is made in moisture sensitivity tests to clarify and understand the mechanisms of moisture damage [1]. The most common technique to mitigate moisture damage is the use of additives or modifiers with the asphalt binder or the aggregate, and AASHTO T-283 is a widely-recognized laboratory test method for the evaluation of moisture susceptibility [2]. Developing laboratory moisture damage evaluation tests is challenging and it is hard to simulate field performance because of the high variability of the factors affecting moisture damage and the process of developing new test procedures still continues [3]. Because of the complexity of the moisture damage phenomenon, it is difficult to find a unique test or analytical method that accurately simulates the field behavior and quantifies and predicts moisture damage [4].

At this point, a discussion topic arises in determining the correct contribution rate. At the point of accurate assessment of field long-term performance, the issue of water damage conditioning models and performance approaches depending on the storage stability of the additives is a rather complex problem. New experimental methods are researched and the subject is examined. Under these circumstances, this research was applied as a widely accepted water damage experiment to evaluate and determine the results of the Modified Lottman test under many different alternatives. Determining the damage ratios and determining the relative effectiveness of the additives (anti-strips or other additives with indirect effects) are widely mentioned in the literature as complex topics. As four different additives, both fatty acid anti-stripping and hydrated lime additives were selected and these additives were used in three different rates in order to evaluate the rate effect. In addition, the applied damage system of the selected Modified Lottman damage test was repeated three times on identical briquettes, and an experimental systematic was created and the effect level of the Modified Lottman test was investigated for the very high damage levels and in this sense, the evaluation of the ratio values and additive activities was made. In this regard, although an experimental method was used in the research, a wide parameter change and an experimental framework were created at the point of complexity of the subject.

Moisture sensitivity is an important pavement degradation mechanism faced by most highway agencies. Along with the complex thermodynamic mechanisms, the subject develops due to various factors in the asphalt mixture. Various types of pavement distress trigger breakdown problems and cause billions of dollars in economic damage through maintenance and rehabilitation practices. The most accepted traditional technique to minimize or prevent water damage is to add additives or modifiers to bituminous mixtures. After all, every additive or modifier put in performance distinctively. Using proper additives and modifiers is considered the most cost-effective technique for mitigating moisture damage. If a particular HMA is determined to be moisture susceptible or sensitive, most U.S. transportation agencies add additives or modifiers to binder or aggregate to make the mix more resistant to moisture damage. The ability of numerous additives and modifiers to reduce stripping potential has been evaluated. Liquid anti-strip and polymers are added to asphalt binder while Portland cement, hydrated lime, and fly ash are added to the aggregates. These additives and modifiers are expected to improve the resistance of HMA to moisture damage by improving the adhesion bond between asphalt binder and aggregate surface. Additives 
and modifiers follow several mechanisms for improving the adhesion bond such as modifying the aggregate surface, promoting the spread of binder around aggregate particles by reducing binder surface tension, or improving the chemical properties of the binder and aggregate surface at the same time [5].

Water damage is not considered to be a damage mode alone, it can speed up other modes of deterioration and cause serious troubles namely bleeding, rutting, raveling and shoving [6, 7]. Existence of moisture in asphalt mixes disrupts mixture structural integrity. It acts upon as a catalyst in the formation of other pavement problems with water damage [8].

To increase durability of the pavement surfaces, adhesion issues between aggregate and bitumen should be understood [9]. To increase the stripping resistance of the mixtures, in general, changes are made to the internal thermodynamic factors, because changes in external factors such as changing the weather and / or traffic are expensive and, in most cases, even impossible. The most important, effective, efficient method to increase the performance of asphalt mixes towards stripping is to choose material properties, mix design or anti-stripping additives. The idea of replacing materials causes to increased transport distances and consequently increases project total costs. Changing the mixture design with unsuitable materials could have an unimportant effect in increasing the resistance of the asphalt mix to water damage [10]. Due to the mineralogical change of aggregate properties and the heterogeneity of the mixtures, it is important to choose the right additive and apply the usage ratios correctly. Even if the mixture design is changed, the problem of stripping may still be a problem for these reasons. The overall equivalent performance feature of the mixtures should be strengthened.

There is great difficulty in obtaining which physicochemical properties are preponderant for adhesiveness, since the mechanisms that govern this property are still not well-understood. Owing to the difficulty in measuring aggregate-binder adhesiveness reliably, most studies attempt to relate this property to moisture damage, but few studies have attempted to explain how this property affects asphalt pavement distresses such as fatigue cracking [11].

Various experiments are available to evaluate the effectiveness of anti-stripping (surfactants) additives, to question and calculate the water sensitivity of asphalt mixes. Experiments could be performed as loose and compacted mix tests [12].

Amines and amidoamines are used as water damage (stripping) inhibitors [13]. Modified Lottman experiment is the most suitable test method available in the context of these experiments and gives high consistency with field performance results $[2,14]$. Although the sensitivity of asphalt mixes to field moisture is estimated correctly, avowable that the Modified Lottman test does not focus on indicating the main characteristics of the respective road making materials. In addition, the proposed index shows asphalt mix resistance to various breaking mechanisms using a number without being interpreted and evaluated. Therefore, the reasons for the proper or poor resistance of an asphalt mix to water damage are unknown until the pavement design engineer redesigned the asphalt mix based on the interpretation of the results $[15,16]$. In the tests carried out with the same type of bitumen without any anti-stripping additives after damage conditioning with the modified Lotmann test; the asphalt mixture consisting of limestone aggregate appears to be more resistant to moisture damage. Asphalt mixtures demonstrate the highest indirect tensile strength ratio 
(TSR) of $61.7 \%$ with limestone aggregate, followed by slate aggregate with $48.6 \%$ and granite aggregate with $58.5 \%$ [17].

Accordingly, a method is needed to determine the effects of bitumen, aggregate and water system on adhesion based on the basic properties of the materials. A better understanding of the adhesion processes between asphalt and aggregate is necessary to extend the durability and life of the pavement materials $[18,19]$.

Caltrans also conducted a statewide field investigation and laboratory testing to determine the severity and major factors conjunction with water damage. The field investigation surveyed the condition of 194 pavement sections that includes dense graded asphalt mixture (DGAC) (now known as HMA), and gap graded rubber modified asphalt concrete (RAC-G) (now known as R-HMA) located in California. About 10 percent of the pavement sections showed moderate to severe moisture damage, which recommended that the evaluation of moisture damage must be considered in assessing the performance of asphalt pavements in California. Also, the effect of variables (such as air void and asphalt cement content) on moisture damage was determined by the laboratory testing, and dynamic loading test procedures were also developed for evaluating moisture sensitivity. Also, the effectiveness of the HWTD and the long-term active effectiveness of hydrated lime and liquid anti-strip additives were evaluated. The results of the laboratory tests are: i) if void contents $\leq 7.0$ percent, dense-graded HMA sections showed little or no moisture damage, but medium or severe moisture damage was observed for void content higher than 7.0 percent, ii) a few RHMA sections with high air void contents (>7\%) showed severe stripping, iii) RHMA sections did not show an advantage in resisting moisture damage over dense-graded HMA, iv) well designed and maintained adequate pavement drainage systems may reduce the moisture damage, and v) HWTD was found to be an effective predictor with a reasonable correlation with field performance. Based on laboratory and field data, hydrated lime and liquid anti-strip agents increased the stripping resistance of asphalt mixtures [20].

The purpose of this research is to investigate the stripping problem, using Modified Lottman tests for different anti-stripping additives (at different rates for fatty acid type and hydrated lime), under different water damage cycling levels, and the effect of their ratios. The problem is questioned under the influence of these parameters.

\section{MATERIALS AND METHOD}

\subsection{Materials}

50/70 penetration grade asphalt cement and basalt rock aggregates were used. Specific properties of bituminous binder and general physical properties of used basalt aggregates were given in Table 1 and Table 2 respectively.

Dense graded aggregate combination (Type-1) was used in accordance with the Turkish Highways Technical Specification [21]. Maximum aggregate size was selected as $19 \mathrm{~mm}$. The aggregate gradation and specification limits were given in Table 3. 
Table 1 - Values of used asphalt cement binder

\begin{tabular}{lll}
\hline Test & Method & Value \\
\hline Specific gravity $\left(25^{\circ} \mathrm{C}\right)$ & ASTM D-70 & 1.014 \\
Softening point $\left({ }^{\circ} \mathrm{C}\right)$ & TS EN 1427 & 48.4 \\
Cleveland flash point $\left({ }^{\circ} \mathrm{C}\right)$ & TS EN ISO 2592 & 324 \\
Penetration $\left(25^{\circ} \mathrm{C}\right)$ & TS EN 1426 & 53 \\
Retaining penetration $(\%)$ & TS EN 12607-1 & 72 \\
Ductility $\left(25^{\circ} \mathrm{C}\right)$ & ASTM D-113 & $100+$ \\
\hline
\end{tabular}

Table 2 - Values of basalt rock aggregates

\begin{tabular}{lll}
\hline Properties & Test Method & Value \\
\hline Specific gravity (coarse agg.) & TS EN 1097-6 & 2.696 \\
Specific gravity (fine agg.) & TS EN 1097-6 & 2.676 \\
Specific gravity (filler) & TS EN 1097-7 & 2.628 \\
Los Angeles abrasion (\%) & ASTM C-131 & 22 \\
Flakiness (\%) & BS 812 (Part 105) & 12.3 \\
Stripping resistance (no additive) (\%) & ASTM D-1664 & $65-70$ \\
Water absorption (\%) & ASTM C-127 & 0.40 \\
Soundness in $\mathrm{MgSO}_{4}(\%)$ & ASTM C-88 & 2.0 \\
\hline
\end{tabular}

Table 3 - Grain size distribution and specification limits

\begin{tabular}{|c|c|c|c|c|c|}
\hline \multicolumn{2}{|c|}{ Sieve size } & \multicolumn{2}{|c|}{ Specification limits } & \multirow{2}{*}{$\begin{array}{l}\text { Aggregate gradation } \\
\text { (\% passing) }\end{array}$} & \multirow[t]{2}{*}{ Aggregate fractions } \\
\hline Inch & $\mathrm{mm}$ & Lower limit & Upper limit & & \\
\hline $3 / 4$ & 19.0 & 100 & 100 & 100.0 & \multirow{3}{*}{ Coarse aggregate, $52 \%$} \\
\hline $1 / 2$ & 12.5 & 88 & 100 & 90.7 & \\
\hline $3 / 8$ & 9.5 & 72 & 90 & 80.0 & \\
\hline No. 4 & 4.75 & 42 & 52 & 48.0 & \multirow{4}{*}{ Fine aggregate, $42.5 \%$} \\
\hline No. 10 & 2.00 & 25 & 35 & 30.5 & \\
\hline No. 40 & 0.425 & 10 & 20 & 14.9 & \\
\hline No. 80 & 0.18 & 7 & 14 & 9.3 & \\
\hline No. 200 & 0.075 & 3 & 8 & 5.5 & Filler, 5.5\% \\
\hline
\end{tabular}


Four different additives were used in the study: hydrated lime, TeraGrip AN (liquid), TeraGrip ANG (solid) and ENEM AP 245 (liquid). TeraGrip AN and TeraGrip ANG are basic form and contain alkylamidopolyamine. Hydrated lime additive contains $84.66 \% \mathrm{CaO}$. All additives were used in three addition ratios. Hydrated lime was substituted for filler in $0.5 \%, 1.0 \%$ and $1.5 \%$ ratios by weight of total dry aggregate, while other additives were incorporated to the bitumen binder in $0.2 \%, 0.4 \%$ and $0.6 \%$ ratios by weight of asphalt cement.

\subsection{Mixture design}

Dense graded asphalt concrete design was done according to the Marshall Design method (ASTM D 1559). Optimum bitumen content was determined using pure bitumen. The optimal asphalt cement content was taken as the percentage of bitumen corresponding to $4 \%$ air voids and determined as $4.75 \%$. The mixture properties obtained from the design results and specification limits were presented in Table 4. Optimum bitumen content determined by pure bitumen was used for modified bitumen options.

Table 4 - Asphalt concrete design results

\begin{tabular}{lll}
\hline Design parameters & Specification limits & Design results \\
\hline Density, gr/cm ${ }^{3}$ & & 2.410 \\
Marshall stability, kg & Min. 900 & 1570 \\
Air voids, \% & $3-5$ & 4.0 \\
Voids filled with asphalt, \% & $65-75$ & 71.0 \\
Flow, mm & $2-4$ & 3.65 \\
Bitumen content, \% & $4-7$ & 4.75 \\
Voids in mineral aggregate, \% & $14-16$ & 14.20 \\
Filler/Bitumen ratio & Max. 1.5 & 1.2 \\
\hline
\end{tabular}

\subsection{Test methods}

In addition to the control mixes, mixtures modified with TeraGrip AN-TeraGrip ANGENEM AP 245 fatty acid derived anti-stripping additives and hydrated lime modified mixtures were produced. A large number of standard Marshall briquettes with a diameter of $101.6 \mathrm{~mm}$ were produced with these control and modified mixtures. The additives were used in three ratios. Asphalt mixtures were evaluated with modified Lottman method for moisture damage resistance. The flow diagram of the study was shown in Figure 1.

Stripping problem or moisture sensitivity is one of the foremost important distress mechanisms in asphalt mixtures. Several tests have been used in the literature to evaluate the stripping problem, but one of the most widely accepted experiments is the Modified Lottman (AASHTO T283) method [22]. In this study Modified Lottman procedure was used for reviewing water sensitivity of the produced asphalt mixture compacted samples. 
Samples used for the Modified Lottman tests were separated in two parts, unconditioned and conditioned samples. The compacted samples in conditioned group were saturated with water between $70 \%$ and $80 \%$ with a vacuum pycnometer. The samples were then covered with a plastic film material and located in a plastic bag containing $10 \mathrm{ml}$ of water. Samples in plastic were kept frozen at $-18^{\circ} \mathrm{C}$ for 20 hours. The samples, which completed the freezing process, were placed in a water bath at $60^{\circ} \mathrm{C}$ for 24 hours without waiting. After water bath, plastic bag and film were removed and conditioning process completed. After samples in conditioned and unconditioned groups were placed in a water bath at $25^{\circ} \mathrm{C}$ for $2 \mathrm{~h}$, indirect tensile strength (ITS) test was made. Using the peak load recorded by test machine and sample sizes, the tensile strengths are calculated by the Equation 1.

$S_{t}=\frac{2000 \cdot P}{\pi \cdot t \cdot D}$

In equation 1: $\mathrm{S}_{\mathrm{t}}$ : indirect tensile strength, $\mathrm{kPa}$; $\mathrm{P}$ : maximum load recorded by test machine, $\mathrm{N}$; t: asphalt briquette thickness, $\mathrm{mm}$; D: asphalt sample diameter, $\mathrm{mm}$.

Moisture susceptibility can be evaluated with tensile strength ratio (TSR). TSR is calculated by dividing the average tensile strength of the samples in the conditioned group by the average tensile strength of the samples in the unconditioned group. Higher TSR means higher resistance to moisture sensitivity. A value of 0.80 can be used as a criterion in the assessment of moisture sensitivity [23].

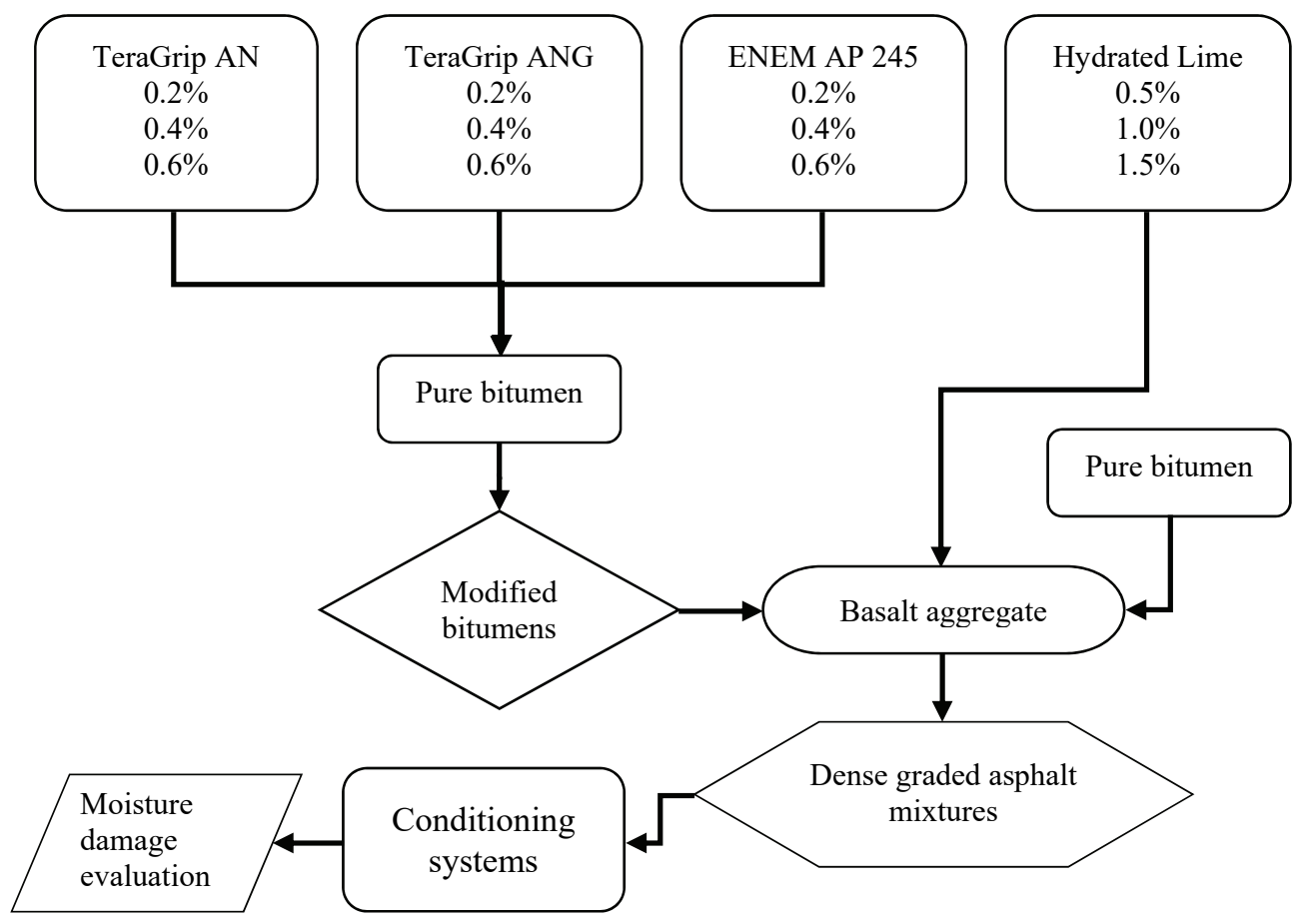

Figure 1 - Flow diagram of the experimental program 


\section{TEST RESULTS AND DISCUSSIONS}

In the study, besides control mixture, four different additives namely TeraGrip AN, TeraGrip ANG, ENEM AP 245, and hydrated lime were examined at three rates. Hydrated lime was used at $0.5 \%, 1 \%$ and $1.5 \%$, while the other additives were added to the bitumen in $0.2 \%$, $0.4 \%$ and $0.6 \%$ ratios. Nine identical samples were produced for each mixture alternative and divided into three groups. The first group was not conditioned; the second group was conditioned with one cycle of modified Lottman procedure and the third group with three cycles of modified Lottman conditioning. The indirect tensile strength test was performed at $25^{\circ} \mathrm{C}$ and tensile strength of mixtures was determined through three tests. Test results were shown in Figures 2-4.

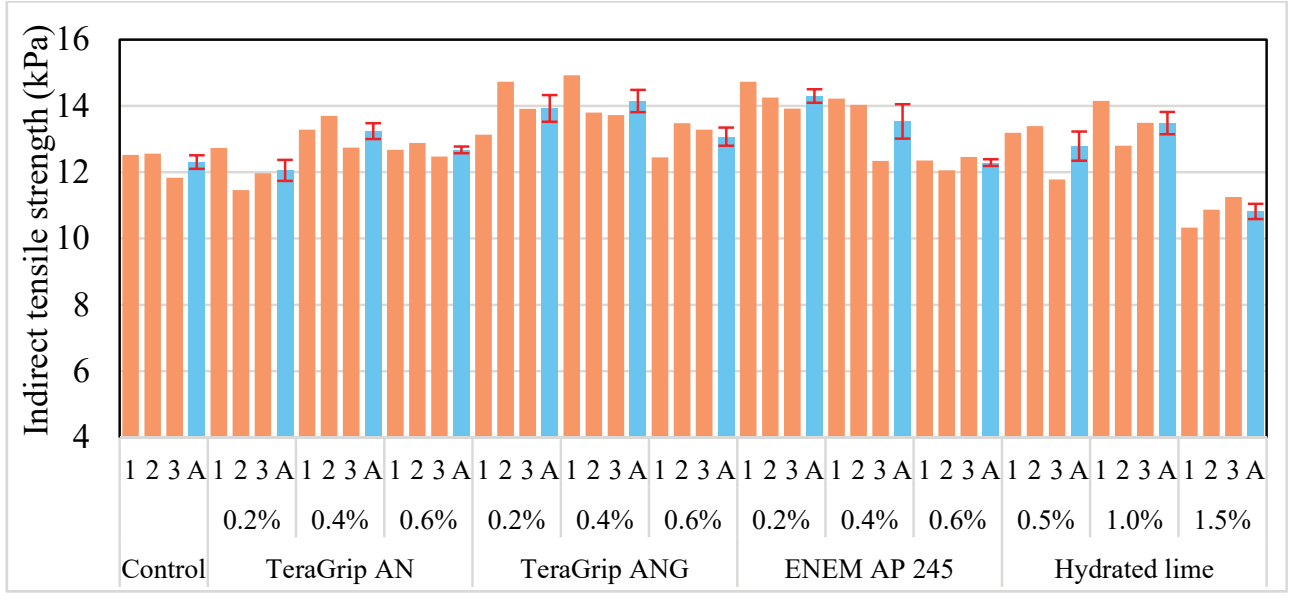

Figure 2 - Tensile strengths of unconditioned mixtures

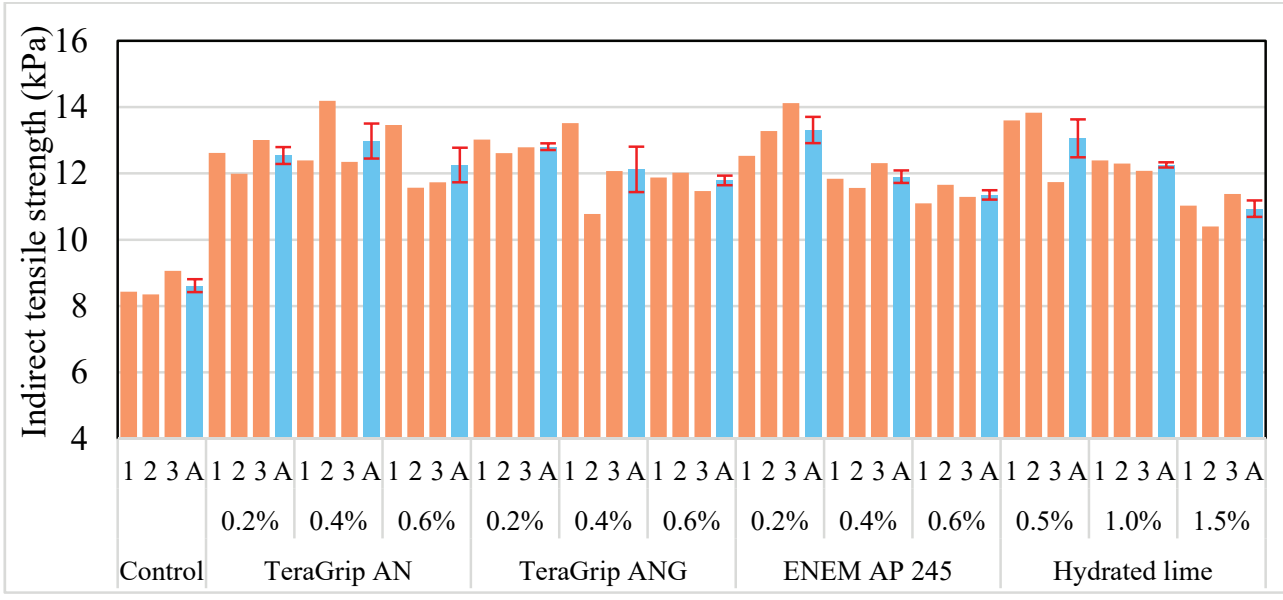

Figure 3 - Tensile strengths of conditioned (1 cycle) mixtures 
The following evaluations may be made for unconditioned mixtures. Indirect tensile strength values of $0.2-0.4-0.5 \%$ selected for fatty amine acid derived anti-stripping additives are obtained higher than the indirect tensile strength of control mixtures ( 9 of 10 mixtures). The liquid additive of $0.2 \%$ TeraGrip gives almost the same value. Hydrated lime additive provides a higher indirect tensile strength for unconditionally $0.5 \%$ and $1 \%$ additives. Indirect tensile strength value decreases at $1.5 \%$ hydrated lime additive ratio. For normal use rates for fatty acid derived anti-stripping additives, the unconditional case has a substantially higher indirect tensile strength value, while the tendency for $0.5 \%$ and $1 \%$ for hydrated lime is the same. In service conditions, it is essential to make these comments under conditional modeling for water damage due to the pavement being exposed to water damage under climatic and traffic impacts.

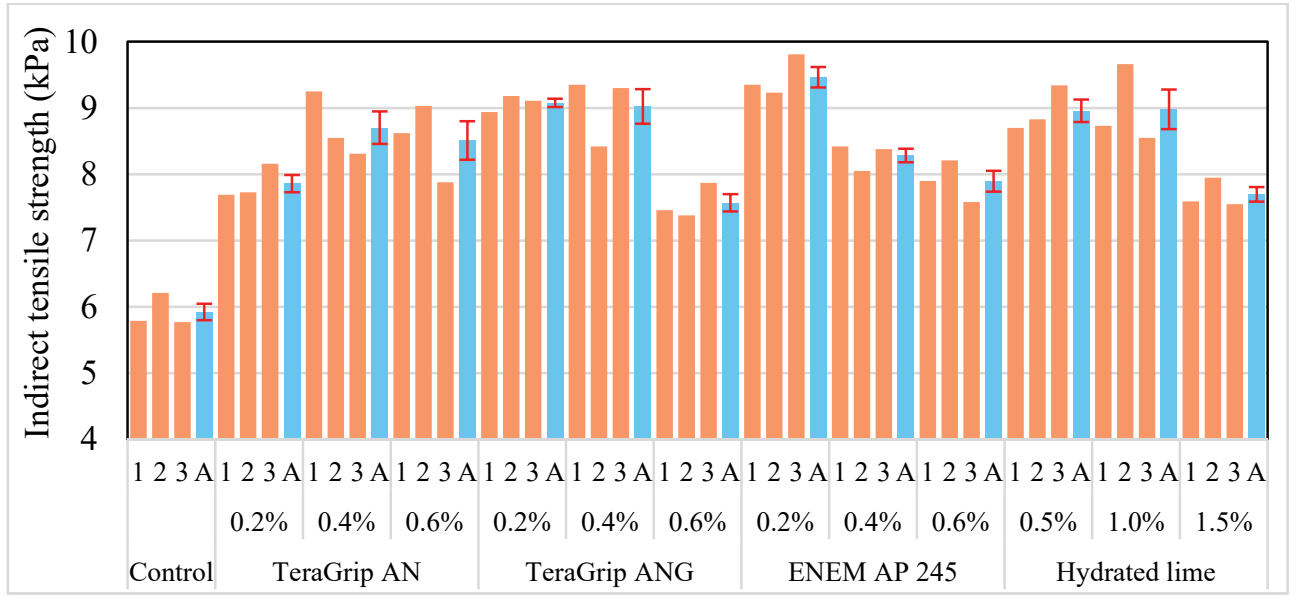

Figure 4 - Tensile strengths of conditioned (3 cycles) mixtures

For single-cycle water damage conditionally, for mixtures; indirect tensile strength values of the control mixture are significantly decreased. This result indicates that there is a significant reduction in the indirect tensile strength of the control mixtures under the single cycle Lottman condition, and that the load spreading capacity of the mixtures is significantly reduced. However, under these single cycle conditions all mixtures with anti-stripping additives (fatty acid amine derived and hydrated lime) exhibit significantly higher strength. Under the water damage model, damaged mixtures with anti-stripping additive clearly indicate their effectiveness, even with unconditional control mixtures, giving high strength values.

Under the three-cycle heavy damage model, strength values continue to decrease. In all cases, however, all anti-stripping additives (modified fatty acid derived and modified lime) produce higher performance improvements. Particularly under active adhesion conditions it is understood that the additives have an important function.

The TSR test has achieved standardization, functioning as a sort of reference and control in a wide variety of countries. This test measures the effect of water on asphalt mixtures by looking at indirect traction; it is suited for dense mixtures made with or without an adhesive 
additive, which come in the form of liquids and powdered solids [24]. The TSR results of the mixtures with one and three cycle conditioning were calculated and presented in Figures 57.

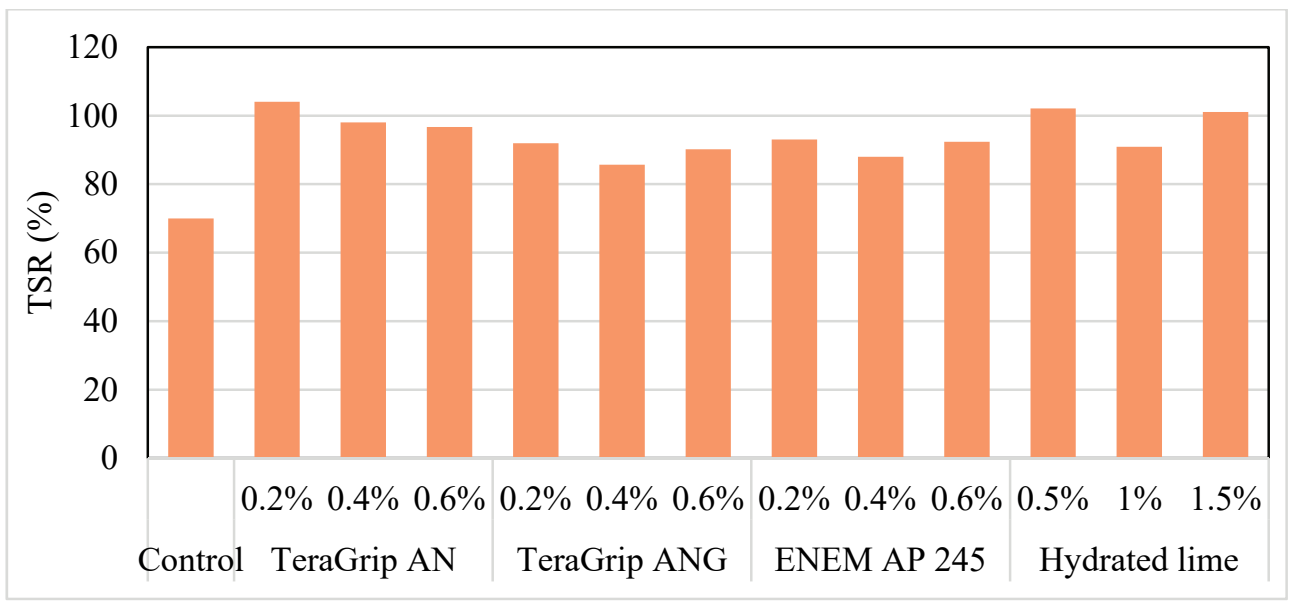

Figure 5 - TSRs (one cycle-conditioned/uncond.) of modified and unmodified mixtures

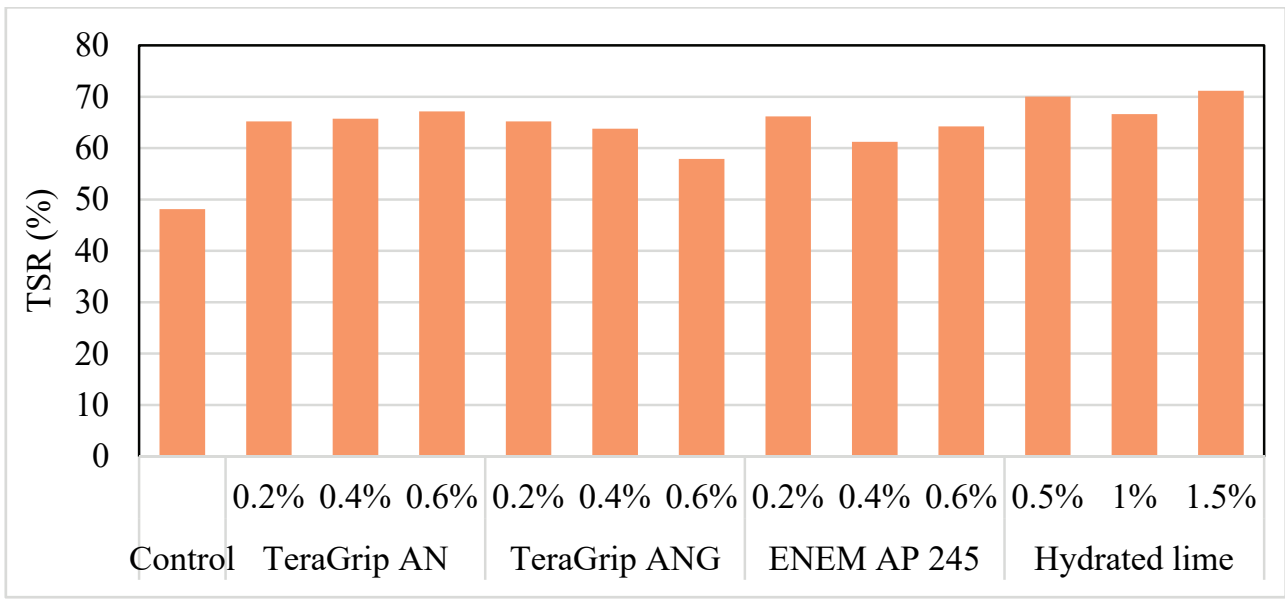

Figure 6 - TSRs (three cycles-conditioned/uncond.) of modified and unmodified mixtures

The proportional changes in tensile strength and TSR values were shown in Table 5 and Table 6 depending on the conditioning systems. Indirect tensile strength values are increased between $30 \%$ and $59.9 \%$ in three different ratios using both fatty acid derived anti-stripping additives and hydrated lime anti-stripping additives. The fact that the samples give higher indirect tensile strength values under the condition of Lottman water damage is interpreted as meaning that the load spreading capacity of the mixtures increases significantly in the 
damaged state. Similarly, the Lottman damage cycle modeling is extended from one cycle to three cycles, resulting in an indirect tensile strength reduction of $1.2 \%$ to $12.1 \%$. This issue; it is understood that the integrity of the mixtures is maintained even if the degree of damage increases considerably.

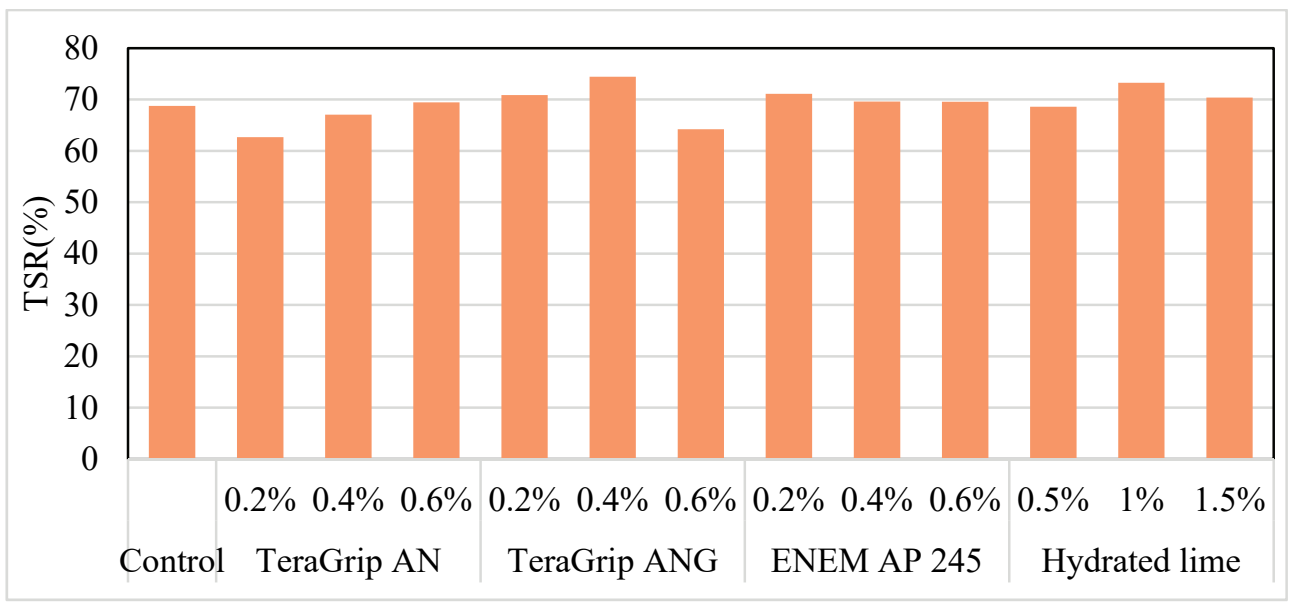

Figure 7 - TSRs (three cycles-conditioned/one cyle-conditioned) of modified and unmodified mixtures

The proportional changes in tensile strength and TSR values were shown in Tables 5 and 6 depending on the conditioning systems. Ratios of tensile strength of modified mixtures due to one cycle damaged modified mixtures to indirect tensile strength of control mixtures can be found greater than $100 \%$, as can be seen in Figure 5. Experiments are carried out on three identical samples. Briquettes are prepared identically with great care. The fact that the indirect tensile strength values given by the additives at certain usage ratios (appropriate usage ratio) can exceed the values of the control mixtures in damaged cases, means that the additives show their function. With the increase in the number of damage cycles, the values decrease below $100 \%$. Another reason for obtaining values higher than $100 \%$ in case of a cycle damage is that the experiments are performed on different identical briquettes. Although identical briquettes are prepared under the same conditions (in terms of mixing parameters), depending on the aggregate angularity values, different values can be obtained depending on the aggregate orientation in the mortar.

Indirect tensile strength values are increased between $30 \%$ and $59.9 \%$ in three different ratios using both fatty acid derived anti-stripping additives and hydrated lime anti-stripping additives. The fact that the samples give higher indirect tensile strength values under the condition of Lottman water damage is interpreted as meaning that the load carrying capacity of the mixtures increases significantly in the damaged state. The indirect tensile strength test is a measure of tensile strength and a good indicator of mixture cohesion. Indirect tensile strength test would provide information on cohesion, specifically asphalt binder stiffness, but not angle of internal friction provided by the aggregates [25]. 
Similarly, the Lottman damage cycle modeling is extended from one cycle to three cycles, resulting in an indirect tensile strength reduction of $1.2 \%$ to $12.1 \%$. This issue; it is understood that the integrity of the mixtures is maintained even if the degree of damage increases considerably.

Table 5 - Variation of tensile strengths depending on the degree of conditioning

\begin{tabular}{|c|c|c|c|c|c|c|c|}
\hline & & $\begin{array}{l}\text { Uncond. } \\
\text { mixtures }\end{array}$ & One cycle & nditioning & Three cy & conditio & \\
\hline & & $\mathrm{I} \% \mathrm{C}_{\mathrm{um}}$ & $\mathrm{I} \% \mathrm{C}_{\mathrm{cm} 1}$ & $\mathrm{I} \% \mathrm{C}_{\mathrm{um}}$ & $\mathrm{I} \% \mathrm{C}_{\mathrm{cm} 3}$ & $\mathrm{I} \% \mathrm{C}_{\mathrm{um}}$ & $\mathrm{I} \% \mathrm{C}_{\mathrm{cm} 1}$ \\
\hline Control & & & & -30 & & -51.9 & -31.2 \\
\hline & $0.2 \%$ & -2.0 & 45.6 & -96.2 & 32.8 & -36.1 & -8.8 \\
\hline $\begin{array}{l}\text { TeraGrip } \\
\text { AN }\end{array}$ & $0.4 \%$ & 7.6 & 50.6 & -95.8 & 47.1 & -29.3 & 1.0 \\
\hline & $0.6 \%$ & 3.0 & 42.2 & -96.5 & 43.8 & -30.8 & -1.2 \\
\hline & $0.2 \%$ & 13.2 & 48.7 & -96.0 & 53.4 & -26.2 & 5.4 \\
\hline TeraGrip & $0.4 \%$ & 15.0 & 40.7 & -96.6 & 52.5 & -26.7 & 4.8 \\
\hline & $0.6 \%$ & 6.2 & 36.9 & -97.0 & 27.9 & -38.5 & -12.1 \\
\hline & $0.2 \%$ & 16.2 & 54.5 & -95.5 & 59.9 & -23.1 & 9.9 \\
\hline $\begin{array}{l}\text { ENEM } \\
\text { A } 245\end{array}$ & $0.4 \%$ & 10.0 & 38.2 & -96.9 & 40.0 & -32.7 & -3.8 \\
\hline & $0.6 \%$ & -0.1 & 31.8 & -97.4 & 33.4 & -35.8 & -8.3 \\
\hline & $0.5 \%$ & 3.9 & 51.6 & -95.8 & 51.3 & -27.2 & 4.0 \\
\hline $\begin{array}{l}\text { Hydrated } \\
\text { lime }\end{array}$ & $1 \%$ & 9.6 & 42.3 & -96.5 & 51.7 & -27.0 & 4.2 \\
\hline & $1.5 \%$ & -12.1 & 27.0 & -97.8 & 30.0 & -37.4 & -10.6 \\
\hline
\end{tabular}

*Increase compared to Control Unconditioned Mixture ( $\left.\mathrm{I} \% \mathrm{C}_{\mathrm{um}}\right)$ *Increase compared to Control-one cycle conditioned mixture $\left(\mathrm{I} \% \mathrm{C}_{\mathrm{cm} 1}\right) *$ Increase compared to Control-three cycle conditioned mixture $\left(\mathrm{I} \% \mathrm{C}_{\mathrm{cm} 3}\right)$

According to the Lottman damage modeling, fatty acid amine-derived additives significantly increase water damage resistance in the selected combination. However, it is seen from Table 6 that the hydrated lime anti-stripping additive used for three different ratios creates a water damage resistance increase between $29.9 \%$ and $45.9 \%$ under Lottman damage modeling. As a result, it is seen that both fatty acid amine anti-stripping additives and hydrated lime significantly increase water damage stripping resistance. Lottman conditioning has an observable level of damage, however, the values of the same fit and development are obtained with the approach of indirect tensile strength ratios.

Water damage level has been increased so as to maintain integrity of the anti-stripping surfactant additive materials in the mixture, to maintain their effectiveness and to see the benefit mechanisms. Lottman water damage conditioning was extended from one cycle to three cycles and reapplied on identical samples. Indirect tensile strength tests were performed 
to found water damage rates after three damage cycles. After three damage cycles, the doped anti-stripping agents mixtures give a higher water damage resistance value for the selected additive ratios, still higher ratios between $20.3 \%$ and $47.8 \%$. This means that the additives remain functional and maintain their mechanisms of benefit, especially in the event of a high degree of damage. While the ratio values of the three damage cycle doped mixtures give a strength reduction of $4.1 \%$ to $17.3 \%$ compared to the ratio values of one damaged modified mixtures, the ratio values are much higher than the conditioned samples. It is seen that the water damage resistance of the mixtures is maintained and increased as the damage level of the additives increases.

Table 6 - Variation of tensile strength ratios according to degree of conditioning degree

\begin{tabular}{|c|c|c|c|c|}
\hline & & \multirow{2}{*}{$\begin{array}{l}\text { One cycle } \\
\text { conditioning } \\
\mathrm{I} \% \mathrm{C}_{\mathrm{cm} 1}\end{array}$} & \multicolumn{2}{|c|}{ Three cycle conditioning } \\
\hline & & & $\mathrm{I} \% \mathrm{C}_{\mathrm{cm} 3}$ & $\mathrm{I} \% \mathrm{C}_{\mathrm{cm} 1}$ \\
\hline \multirow[t]{2}{*}{ Control } & & & & -31.2 \\
\hline & $0.2 \%$ & 48.6 & 35.4 & -6.9 \\
\hline \multirow{2}{*}{$\begin{array}{l}\text { TeraGrip } \\
\text { AN }\end{array}$} & $0.4 \%$ & 40.0 & 36.5 & -6.1 \\
\hline & $0.6 \%$ & 38.1 & 39.5 & -4.1 \\
\hline \multirow{3}{*}{$\begin{array}{l}\text { TeraGrip } \\
\text { ANG }\end{array}$} & $0.2 \%$ & 31.4 & 35.4 & -6.9 \\
\hline & $0.4 \%$ & 22.4 & 32.5 & -8.9 \\
\hline & $0.6 \%$ & 28.9 & 20.3 & -17.3 \\
\hline \multirow{3}{*}{$\begin{array}{l}\text { ENEM } \\
\text { AP } 245\end{array}$} & $0.2 \%$ & 33.0 & 37.5 & -5.5 \\
\hline & $0.4 \%$ & 25.7 & 27.2 & -12.6 \\
\hline & $0.6 \%$ & 31.9 & 33.5 & -8.2 \\
\hline \multirow{3}{*}{$\begin{array}{l}\text { Hydrated } \\
\text { lime }\end{array}$} & $0.5 \%$ & 45.9 & 45.5 & 0.1 \\
\hline & $1 \%$ & 29.9 & 38.4 & -4.8 \\
\hline & $1.5 \%$ & 44.4 & 47.8 & 1.6 \\
\hline \multicolumn{5}{|c|}{$\begin{array}{l}\text { *Increase compared to Control Unconditioned Mixture }\left(\mathrm{I} \% \mathrm{C}_{\mathrm{um}}\right) * \text { Increase compared to } \\
\text { Control-one cycle conditioned mixture }\left(\mathrm{I} \% \mathrm{C}_{\mathrm{cm} 1}\right) * \text { Increase compared to Control-three } \\
\text { cycle conditioned mixture }\left(\mathrm{I} \% \mathrm{C}_{\mathrm{cm} 3}\right)\end{array}$} \\
\hline
\end{tabular}

For Lottman water damage ratios, it can be said that the Lottman test clearly demonstrates its superiority in this sense, as it can be distinctive in terms of comparing the mixing performances even if the number of damage cycles is increased from one to three.

Also, the addition of an anti-stripping additive will increase the resistance of the asphalt mixture against moisture damage. It can be seen that the TSR value recorded in asphalt mixes created by adding anti-stripping additives such as limestone powder is very high compared to the asphalt mix without anti-stripping additives. With base type bitumen and aggregate, 
values are $48 \%$ and $60 \%$ [26]. This can also be seen in studies showing a high TSR rate of 72 to $95.2 \%$ in asphalt mixes, compared to the addition of anti-stripping additives [17], without any additives in the range of $48 \%$ to $61.7 \%$.

For asphalt mixtures, when it is formed by adding limestone aggregate, modified bitumen and anti-stripping additives, it is seen that it will be more resistant to moisture damage. This result is similar in other researches [27-29]. Hydrated lime tends to be the most popular among anti-strip additives because it has been shown to be effective in increasing the moisture resistance of the asphalt mixture. While polymer modified bitumen is the most popular in asphalt mix design, it shows more moisture damage resistance than the commonly used asphalt binder. In general, it is emphasized that the Modified Lottman test, Immersion Compression test and Boiling Water test are reliable tests in evaluating the moisture sensitivity of the asphalt mixture [30].

Hydrated lime-doped mixtures were also noteworthy. In particular, when the Lottman damage cycle number is applied in three cycles, when the indirect tensile strength ratios are evaluated, the hydrated lime modified mixtures generally show higher ratio increases, often compared to other admixture and fatty acid amine anti-stripping additives. As a descriptor of water damage and a performance indicator, it has been wondered how the indirect tensile strength values will change with respect to hydrated lime modified mixtures if the damage level increases further. Further research will focus on the topic.

A second common preservative additive is hydrated lime. Hydrated lime works similar to amine-based anti-peel additives, because its primary purpose is to modify the electrical charge of the constituent materials. The difference is that hydrated lime allows to change the surface charge of aggregates from negative to positive and to produce better adhesion with asphalt binders (tendency to be negative). Lime is often mixed in slurry form or directly into moist aggregates, as it needs moisture to activate it. The use of lime has been approved by many organizations and is included as part of the specifications. The added benefit of slaked lime is that it acts as an "active" filler that hardens the bituminous binder and helps to increase friction resistance, especially in hot and wet conditions [31].

The use of solid and liquid anti-stripping additives is one of the effective solutions for strengthening the adhesion between aggregates and asphalt cement and for the wettability of the aggregate. The use of liquid anti-strips dates back to the 1930s, and such materials are not sufficiently sustainable at high temperature exposure [32].

Adding certain anti-stripping surfactants from Evonik and Zycotherm to the mixes creates a stronger adhesion between asphalt cement and aggregates. Dynamic behavior response of modified bituminous mixtures is increased. These nanomaterials form a covalent bond between the bituminous binder and the aggregate and prevent the penetration of moisture at the bitumen aggregate interface through a hydrophobic layer. The resistance of bituminous mixtures to water damage can be increased by using anti-stripping agents. Evonik as a newly introduced additive, Zycotherm as a common nanomaterial and hydrated lime; to evaluate and compare the effects of asphalt mixes on moisture damage and other performance properties. Moisture sensitivity was evaluated using indirect tensile strength (modified Lottman) and Texas Boiling tests. In other respects; Marshall, Resilient Modulus and Dynamic Creep tests were also applied. All three additives increase the moisture resistance of asphalt mixes, and the mixture containing 0.1 percent Zycotherm has the best performance. 
Hydrated lime has the best effect to increase the rutting resistance of asphalt mixes due to the hardening effect on the mixtures. Among the considered dosages of nanomaterials, the optimum amounts of Zycotherm and Evonik are $0.1 \%$ and $0.3 \%$, respectively, based on the weight of the bitumen binder. The first contributes to a $15 \%$ increase in ITS, and the second increases ITS values by $9 \%$ [23].

The moisture susceptibility of asphalt mixtures modified with Zycosoil as a nanoorganosilane antistripping agent and the hydrated lime in the form of slurry was evaluated. Because the siliceous aggregates are more moisture susceptible than the limestone aggregates, two asphalt mixtures made from these aggregates were sampled to capture the effects of Zycosoil on stripping damage. Siliceous aggregate based asphalt mixtures, the Zycosoil had better performance in enhancing the resistance of the mixture against water damage. Also, in mixtures with limestone aggregates, the limestone filler material had slightly better performance than the Zycosoil [33].

The effects of Zycosoil in moisture susceptibility of glassphalt mixtures were interrogated. It was obtained that mixtures containing $4.5 \%$ zicosoil by the weight of the bitumen binder had best performance in mechanical and anti-stripping properties [34].

The moisture susceptibility of asphalt mixtures modified with Wetfix and Tackamin-200 was studied. These additives at $0.0,0.4,0.5$ and 0.6 percent by the weight of bitumen were added to mixtures. The mixture containing $0.5 \%$ of nanoclay had highest resistance against water induced damage [35].

The effects of liquid anti-strip, hydrated lime, SBS, and PPA on HMA stripping susceptibility were evaluated through selected laboratory tests, covering the modified Lottman AASHTO T283-02 test with five FT cycles, wheel track test, and a fracture test using SCB specimens. It was concluded anti-strip additive and hydrated lime are effective in reducing water damage potential [5].

The effect of aggregate gradation, hydrated lime, and Sasobit additive on moisture damage using indirect tensile tests and response surface method was researched. Dry samples had better mixing behavior with bituminous binder than wetted samples. The TSR value of mixture samples with hydrated lime content ranging from $1.1 \%$ to $2.5 \%$, Sasobit content from $0.5 \%$ to $2.5 \%$, and fine aggregates from $66 \%$ to $74 \%$ was greater than $80 \%$ [36].

Anti-stripping agents of hydrated lime and Zycosoil modified mixtures had nearly similar dry tensile strength but the saturated ITS values were better than control mixtures. The effect of lime and Zycosoil on tensile strength of samples in wet condition was same. adding antistripping agents, TSR values for all the mixtures satisfied the standard requirement and the specimens showed favorable behavior against moisture. Zycosoil with concentrations about $5 \%$ of hydrated lime had good performance in cutting into the stripping damage of warm mix asphalt (WMA) mixtures [37].

The values of indirect tensile strength test may be used to evaluate the relative quality of bituminous mixtures in conjunction with laboratory mix design testing and for estimating the potential for rutting or cracking. The results can also be used to determine the potential for field pavement moisture damage when results are obtained on both moisture-conditioned and unconditioned specimens [38]. For additive alternatives; indirect tensile strength values 
increase between 30 and 59.9\%. Therefore, it is understood that the load-spreading capacity of the mixtures in the damaged state increases significantly.

By increasing the damage level to three cycles, indirect tensile strength decreases between $1.2 \%$ and $12.1 \%$. This issue; even if the degree of damage is considerably increased, the integrity of the mixtures is maintained.

Indirect tensile strength ratios increase from $20 \%$ to $48 \%$. Among the anti-stripping additives of the fatty acid type, the teraGrip AN additive offers higher rates in all three ratio options. Increasing rates means increased resistance to water damage. According to the Lottman damage modeling, fatty acid amine-derived additives significantly increase water damage resistance in the selected combination.

Modified Lottman water damage test with indirect tensile test; if the number of water damage cycle modeling applied is increased from one cycle to three cycles, the ratios of water damage appear to decrease. This topic shows that the Modified Lottman test will be used successfully to predict long-term field performance. It is not possible to evaluate the ratios obtained at different rate levels of the same additive in a linear manner, although in all cases a higher ratios of water damage is obtained compared to additives. It is considered that it will be more beneficial to use the contributions at a low ratio in the context of the economic principle. However, it is considered an imperative that low ratio addition is included in the evaluation of the relative effectiveness of different additives, especially in the long-term performance mix test tests for quality performance.

\section{CONCLUSIONS}

It is possible to draw the following conclusions from the research.

- When the indirect tensile strength test results are interpreted as a sign of mixture cohesion, it is considered that the cohesion of all mixtures with additives increases.

- With the application of three cycles of the Modified Lottman conditioning cycle, the admixtures still retain their structural integrity.

- Both fatty acid amine anti-stripping additives and hydrated lime significantly increase water damage resistance.

- The anti-stripping additives remain effective even when the Modified Lottman water damage conditioning is applied repeatedly as three times.

- Modified Lottman test was found to be highly effective in determining stripping behavior. It was distinguished both at its own damage level and at increased damage levels.

- At the economic approach point, it can be proposed as a control mechanism in which low addition ratios can be selected. As the determination of the relative effectiveness of different additives and price analysis, it is considered an imperative to perform field simulated tests, such as the Hamburg wheel tracking test that may reflect long-term performance, for the process of deciding the ratio of use. The anti-stripping additives should be used at low ratios, but long-term performance needs to be checked by wheel track tests. 


\section{Symbols}

$\begin{array}{ll}\text { AS } & \text { : Fatty amine acid } \\ \text { HL } & \text { : Hydrated lime } \\ \text { HMA } & \text { : Dense graded asphalt } \\ \text { ITS } & \text { : Indirect tensile strength } \\ \text { ITSR } & \text { : Indirect tensile strength ratio } \\ \text { RHMA } & \text { : Rubber modified asphalt } \\ \text { WMA } & \text { : Warm mix asphalt }\end{array}$

\section{References}

[1] Diab, A., You, Z. Development of a realistic conditioning and evaluation system to study moisture damage of asphalt materials. In Airfield and Highway Pavement 2013: Sustainable and Efficient Pavements, 1008-1017, 2013.

[2] Solaimanian, M., Harvey, J., Tahmoressi, M., Tandon, V. Test methods to predict moisture sensitivity of hot-mix asphalt pavements. In Transportation research board national seminar. San Diego, California, 77-110, 2003.

[3] Al-Qadi, I.L., Abuawad, I.M., Dhasmana, H., Coenen, A.R., Trepanier, J.S. Effects of Various Asphalt Binder Additives/Modifiers on Moisture-Susceptible Asphaltic Mixtures Research Report FHWA-ICT-14-004, University of Illinois, Urbana, 2014.

[4] Caro, S., Masad, E., Bhasin, A., Little D.N. Moisture susceptibility of asphalt mixtures, Part 2: Characterization and modeling. Int J Pavement Eng 9(2), 99-114, 2008.

[5] Abuawad, I. M., Al-Qadi, I. L., Trepanier, J. S. Mitigation of moisture damage in asphalt concrete: Testing techniques and additives/modifiers effectiveness. Construction and Building Materials, 84, 437-443, 2015.

[6] Sebaaly, P. E., Hitti, E., Weitzel, D. Effectiveness of lime in hot-mix asphalt pavements. Transportation Research Record, 1832(1), 34-41, 2003.

[7] Wasiuddin, N. M., Fogle, C. M., Zaman, M. M., O'Rear, E. A. Effect of antistrip additives on surface free energy characteristics of asphalt binders for moisture-induced damage potential. Journal of testing and evaluation, 35(1), 36-44, 2007.

[8] Airey, G. D., Collop, A. C., Zoorob, S. E., Elliott, R. C. The influence of aggregate, filler and bitumen on asphalt mixture moisture damage. Construction and building materials, 22(9), 2015-2024, 2008. 
[9] Cui, S., Blackman, B. R., Kinloch, A. J., Taylor, A. C. Durability of asphalt mixtures: Effect of aggregate type and adhesion promoters. International Journal of Adhesion and Adhesives, 54, 100-111, 2014.

[10] Epps, J., Berger, E., Anagnos, J. N. Moisture Sensitivity of Asphalt Pavements: Treatments. In A National Seminar, Transportation Research Board, San Diego, California, 77-177, 2013.

[11] Júnior, J. L. L., Babadopulos, L. F., Soares, J. B. Moisture-induced damage resistance, stiffness and fatigue life of asphalt mixtures with different aggregate-binder adhesion properties. Construction and Building Materials, 216, 166-175, 2019.

[12] Solaimanian, M., Bonaquist, R. F., Tandon, V. Improved conditioning and testing procedures for HMA moisture susceptibility (Vol. 589). Transportation Research Board, 2007.

[13] Xiao, F., Amirkhanian, S. N. Effects of liquid antistrip additives on rheology and moisture susceptibility of water bearing warm mixtures. Construction and Building Materials, 24(9), 1649-1655, 2010.

[14] Lottman, R., Johnson, D. L. Pressure-induced stripping in asphaltic concrete. Highway Research Record, 340, 13-28, 1970.

[15] Lottman, R. P. Laboratory test methods for predicting moisture-induced damage to asphalt concrete. Transportation Research Record, 843, 1982.

[16] Hamedi, G. H., Moghadas Nejad, F. Evaluating the effect of mix design and thermodynamic parameters on moisture sensitivity of hot mix asphalt. Journal of Materials in Civil Engineering, 29(2), 04016207, 2017.

[17] Khosla, N., Birdsall, B. G., Kawaguchi, S. Evaluation of moisture susceptibility of asphalt mixtures: conventional and new methods. Transportation Research Record, 1728(1), 43-51, 2000.

[18] Blackman, B. R., Cui, S., Kinloch, A. J., Taylor, A. C. The development of a novel test method to assess the durability of asphalt road-pavement materials. International Journal of Adhesion and Adhesives, 42, 1-10, 2013.

[19] Horgnies, M., Darque-Ceretti, E., Fezai, H., Felder, E. Influence of the interfacial composition on the adhesion between aggregates and bitumen: Investigations by EDX, XPS and peel tests. International Journal of Adhesion and Adhesives, 31(4), 238-247, 2011.

[20] California Department of Transportation, California Test Methods, Materials, Engineering and Testing Services, http://www.dot.ca.gov/hq/esc/ctms. (Accessed October 31, 2017).

[21] General Directorate of Highways of Turkey, Highway Technical Specifications, General Directorate of Highways of Turkey, 2013, Ankara, Turkey.

[22] Mirhosseini, A. F., Tahami, S. A., Hoff, I., Dessouky, S., Ho, C. H. Performance evaluation of asphalt mixtures containing high-RAP binder content and bio-oil rejuvenator. Construction and Building Materials, 227, 116465, 2019. 
[23] Ameri, M., Vamegh, M., Naeni, S. F. C., Molayem, M. Moisture susceptibility evaluation of asphalt mixtures containing Evonik, Zycotherm and hydrated lime. Construction and Building Materials, 165, 958-965, 2018.

[24] Figueroa, A.S. and Reyes, F.A. Moisture damage analysis through the TSR and MIST test using water conditioning asphalt, 6th Eurasphalt \& Eurobitume Congress 1-3 June 2016, Prague, Czech Republic.

[25] Srinivasan, G. Evaluation of indirect tensile strength to identify asphalt concrete rutting potential, Graduate Theses, Dissertations, and Problem Reports, 1465, 2004, West Virginia University.

[26] Abo-Qudais, S. The effects of damage evaluation techniques on the prediction of environmental damage in asphalt mixtures. Building and Environment, 42(1), 288-296, 2007.

[27] Lavin, P. Comparison of liquid antistrip additives and hydrated lime using AASHTO T-283. Construction chemicals technical director, ARR-MAZ products, 1999.

[28] Uddin, W. Viscoelastic characterization of polymer-modified asphalt binders of pavement applications. Applied Rheology, 13(4), 191-199, 2003.

[29] Aman, M. Y., Shahadan, Z., Noh, M., Zaime, M. A Comparative study of anti-stripping additives in porous asphalt mixtures. Jurnal Teknologi, 70(7), 139-145, 2014.

[30] Taib, A., Jakarni, F. M., Rosli, M. F., Yusoff, N. I. M., Aziz, M. A. Comparative study of moisture damage performance test. In IOP Conference Series: Materials Science and Engineering, 512 (1), 012008, 2019.

[31] Dave, E. V. Moisture Susceptibility Testing for Hot Mix Asphalt Pavements in New England. Prepared for The New England Transportation Consortium, August 2018, NETCR109 Project No. 15-3, University of New Hampshire 105 Main Street Durham, NH, 03824, 2018.

[32] Ford Jr, M. C., Manke, P. G., O'Bannon, C. E. Quantitative evaluation of stripping by the Surface Reaction Test, No. 517, 1974.

[33] Ameri, M., Kouchaki, S., Roshani, H. Laboratory evaluation of the effect of nanoorganosilane anti-stripping additive on the moisture susceptibility of HMA mixtures under freeze-thaw cycles. Construction and Building Materials, 48, 1009-1016, 2013.

[34] Behbahani, H., Ziari, H., Kamboozia, N., Khaki, A. M., Mirabdolazimi, S. M. Evaluation of performance and moisture sensitivity of glasphalt mixtures modified with nanotechnology zycosoil as an anti-stripping additive. Construction and Building Materials, 78, 60-68, 2015.

[35] Imaninasab, R., Joodaki, S. Performance evaluation of polyamine anti-stripping additives. Proceedings of the Institution of Civil Engineers-Construction Materials, 172(3), 155-163, 2019.

[36] Kavussi, A., Qorbani, M., Khodaii, A., Haghshenas, H. F. Moisture susceptibility of warm mix asphalt: a statistical analysis of the laboratory testing results. Construction and Building Materials, 52, 511-517, 2014. 
[37] Omrani, H., Ghanizadeh, A. R., Tanakizadeh, A. Effect of SBS Polymer and Antistripping Agents on the Moisture Susceptibility of Hot and Warm Mix Asphalt Mixtures. Civil Engineering Journal, 3(10), 987-996, 2017.

[38] ASTM Designation: D6931 - 12. Standard Test Method for Indirect Tensile (IDT) Strength of Bituminous Mixtures, ASTM International, 100 Barr Harbor Drive, PO Box C700, West Conshohocken, PA 19428-2959. United States. 